The Constructivist Approach to Curriculum Integration of STEM Education Jessica Patel

McGill University 


\begin{abstract}
Teachers feel that by integrating a little sprinkle of technology and engineering mixed in mathematics and science is enough to integrate STEM across all four disciplines. This shows how one of the biggest educational challenges for K - 12 STEM education is that few general guidelines or models exist for teachers to follow regarding how to teach using STEM integration approaches in their classroom. This also goes to show how the most common conception of STEM education might be the notion of integration - meaning that STEM is the purposeful integrations of the various disciplines as used in solving real - word problems. Despite the benefits of integrated curricula seem clear, there are barriers that must be negotiated when teachers choose to implement integrated STEM curricula. Therefore, the focus of this literature review will also be on quantitative studies that provide information on teachers continuously using a traditional instruction contradicting the definition of integrated STEM education. To implement effective integrated STEM education, attention has been paid to teachers' using constructivist teaching strategies to implement integrated STEM education that can help students gain interest in STEM subjects.
\end{abstract}

\title{
Introduction
}

In the past decade, the federal government had made STEM a top priority in funding since a growing concern about developing America's future scientists, technologists, engineers, and mathematicians to remain viable and competitive in the global economy. Essentially, this has raised attention to STEM education (Breiner, Harkness, Johnson \& Koehler, 2012; Wang, Moore, Roehrig \& Park, 2011; Radloff \& Guzey, 2016). The global competitiveness and growing workforce needs in the fields of science, technology, engineering and mathematics (STEM) disciplines is dependent upon our educational system's ability to function as a catalyst 
for economic growth by both educating and recruiting students into the STEM disciplines at the $\mathrm{K}-12$ and the post-secondary levels (Breiner., et al, 2012; Huntley, 1998; Wang et al., 2011). For instance, the Obama - Biden Plan (2009) assured integrated STEM education and resources for development in education as a response to the poor performance of United States students in mathematics and science (Breiner et al., 2012). While the government have made many plans and policies for advocating STEM integration in classrooms, there is yet no common understanding of what strategies can be used in integrated STEM instruction in theory or in practice as it remains ill-defined, with many gaps in existing research (Breiner et al., 2012, Huntely, 1998; Kelley \& Knowles, 2016; Radloff \& Guzey, 2016; Stohlmann, 2018; Wang et al., 2011).

Additionally, over the past several years, common questions that I have heard in many of my own mathematics classrooms is "why do I need to know this?", "when will I ever use this" or "just give me the formula, and I can work the problem"? Many research studies have linked these situations to the still - dominant traditional model of instruction and curricula of rote memorization (Anthony, 1996; Kyriacou, 1992; Huntely, 1998; Simon, 1995; Wang et al., 2011) of concepts for mathematics and science classrooms or the depth of knowledge is often determined through one final essay or presentation in other fields (Clements \& Battista, 1990). Following these lessons, teachers give a "drill and practice" homework assignment over the same concepts that were covered in class (Crawford \& Witte, 1990). This method of instruction would continue day after day with minimal critical thinking skills obtained by learners. Most importantly, this instruction does not reveal how STEM is relevant to the student's lives. Studies have found that roughly 40 percent of students planning engineering and science majors end up switching to other subject's in post-secondary education (Breiner et al., 2012). Existing research 
(Kelly \& Knowles 2016; Wang et al., 2011) has related this to educators being aware of the importance of STEM education but neither educators nor researchers consistently decide or understand what STEM education should really be about.

With a proper focus on integrated approaches to STEM education, it can help the next generation of students to solve real-world problems by applying concepts that cut across disciplines as well as capacities of critical thinking, collaboration, and creativity (Breiner et al., 2012; Huntely, 1998; Ring, Dare, Crotty \& Roehrig, 2017; Wang et al., 2011). However, most teachers have received training in only one discipline, and most schools and classes at all levels still have separate departments and class periods for the STEM subjects (Ring et al., 2017). For teachers to help learners develop skills for a growing workforce, teachers must have the capability to integrate STEM into their teaching process, as the approach is expected to take the role as the primary learning medium in the future (Stohlmann, 2018). Thus, now legislators are beginning to focus on strategies that will improve the overall quality of education to prepare students for jobs in a 21 st-century workforce. For this reason, this literature reviews attention was paid to teachers' implementation practices and perceptions of the most effective ways for their students to learn and engage with STEM concepts through effective roles of teachers in integrated STEM classrooms.

\section{Conceptual framework for integrated STEM education}

As STEM is made up of four disciplines, one concern is the perception that ' $T$ ' (technology) and ' $E$ ' (engineering) are sometimes overlooked as secondary to the ' $\mathrm{S}$ ' (science) and 'M' (mathematics) (Wang et al., 2011). In this conceptualization, content integration is at the heart of STEM education. However, there are multiple ways in which to carry this out (Breiner et al., 2012; Kelly \&Knowles, 2016; Huntley, 1998; Wang et al., 2011). For example, Kelley and 
Knowles (2016) define integrated STEM education as "the approach to teaching the STEM content of two or more STEM domains, bound by STEM practices within an authentic context for the purpose of connecting these subjects to enhance student learning” (p. 3). While Breiner et al. (2012) define the practice of STEM integration as the shift from traditional lecture-based classrooms to the implementation of pedagogy that involves more inquiry and problem - based approaches. On the other hand, Wang et al. (2011) identified an integrated STEM with three principles: “(1) deepen student understanding of each discipline by contextualizing concepts, (2) broaden student understanding of STEM disciplines through exposure to socially and culturally relevant STEM contexts, and (3) increase interest in STEM disciplines by increasing the pathways for students to enter the STEM fields" (p. 2).

Consequently, in direct opposition to traditional mathematics', National Council of Teaching Mathematics (NCTM) has proposed for more student-centered learning where the learner is at the center of the learning process, whereby deemphasizing rote memorization of isolated skills and facts (Draper, 2002; Simon 1995). This reform-oriented instruction comes from Piaget's (1920) learning theory of constructivism (Anthony, 1996; Breiner et al., 2012; Caswell \& LaBrie, 2017; Yackle \& Cobb, 1996; Draper, 2002; Kelley \& Knowles, 2016; Maab \& Artigue, 2013; Simon, 1995; Wang et al., 2011). While traditional instruction focuses on authoritative and teacher-centered traditional classrooms in which the teacher stands at the front of the room directing the content that is delivered and teaches STEM disciplines in silo (Clements \& Battista, 1990; Draper 2002; Huntley, 1998), constructivism asserts that individuals approach a new task with prior knowledge, integrate new information, and do more than impart knowledge (Anthony, 1996; Crawford \& Witte, 1990, Kelley \& Knowles, 2016; Wang et al., 2011). 
I chose to use Wang et al's., (2011) theoretical framework to organize my findings because of its simplicity and accessibility for teachers at all levels of competency. In their theory, they use curriculum integration as an effective tool for teachers to implement integrated STEM education in their classrooms. The concept of integration is complex and challenging; curriculum integration is more than simply putting different subject areas together in the same lesson. Wang et al., (2011) defined curriculum integration using four major aspects: “(a) the integration of experience where learning involves integrating past experiences, (b) the social integration whereby learners share knowledge, and (c) the integration as a curriculum design which emphasizes on the construction of knowledge through active learning" (p. 3). On the other hand, Ring et al., (2017) suggest that using an integrated curriculum provides students with a highly relevant, less fragmented, and more stimulating learning experience than curricula that are not integrated. Studies have shown that integration allows students to apply their knowledge and encourage them to examine relationships between multiple concepts. In addition, another theoretical underpinning of effective integrated STEM education the authors suggests that a STEM integrated classroom should be a place where students are able to perform as "1) problem - solvers, 2) innovators, 3) inventors, 4) logical thinkers, and also be able to understand and develop the skills needed for 5) self-reliance and 6) technological literacy" (Wang et al., 2011, p. 3). Therefore, the focus of the integration approach demonstrates that curriculum integration was grounded in the tenants of constructivism which I report our results based on these tenets through. 


\section{Method}

I utilized three online databases (Google Scholar, McGill Library and JSTOR) and pieces of literature from EDEC 624 at McGill University, Montreal. During my search, I chose the terms "constructivism in integrated STEM education", "curriculum integration strategies", "constructivist classroom strategies" and "teacher's role in an integrated STEM classroom" as a means of managing a systematic search. The choice of articles focused on reading abstracts of literature which focused primarily on the role of a teacher in a constructivist classroom and strategies used in implementing inquiry-based learning. My search yielded 17 classrooms based research studies from 199 to 2018 , highlighting constructivist instruction embraced in classrooms. Most of the literature adopted ethnography in their studies using videotapes as an observational tool and ethnographic interviews that gave descriptive accounts. Lastly, to synthesize the literature and organize my research I made a table which showed a visual representation of the main ideas found in the literature and also shows where there is overlap in ideas between authors. By synthesizing how other educators have implemented constructivist, the paper will assist pre-service teachers, in-service teachers and teacher educators in developing what their role in a constructivist classroom can 'look like'

\section{Results of Review}

\section{Strategies for Teachers to Implement Integrated STEM education}

The discussion above forms the basis of my research question on how teachers' can implement effective integrated STEM education and their role in such a classroom. Altogether, it becomes clear that the strategies for implementation of constructivism need to be selected 
carefully so that they fully engage the students' higher mental capacities (Anthony, 1996; Briener et al., 2012; Caswell \& LaBrie, 2017; Maab \& Artigue, 2013; Simon, 1995, Radloff \& Guzey, 2016; Wang et al., 2011). Diverse learning strategies such as problem based learning (Anthony, 1996; Yackle \& Cobb, 1996; Kyriacou, 1992; Maab \& Artigue, 2013; Simon, 1995), group discussions (Anthony, 1996; Caswell \& LaBrie, 2017; Kyriacou, 1992; Maab \& Artigue, 2013; Simon, 1995) and self-assessment (Diezmann, 2004) are forms of curriculum integration strategies which will be discussed for effective integrated STEM classroom. In addition, the focus on teachers' content knowledge (Mishra \& Koehler, 2006; Shulman 1986) is an important primary tool for teachers to focus on the diverse strategies listed.

\section{Focusing on Teacher's Content Knowledge}

Integrating science, technology, engineering, and mathematics presents challenges to teachers whose background knowledge in several of the subject areas is limited (Wang et al., 2011). For example, teachers need to be confident with using the technology, know the content they want to teach, and the pedagogical strategies needed to teach the content with the technology (Mishra \& Koehler, 2006). Based on Shulman’s (1986) pedagogical content knowledge (PCK) convinced researchers that understanding such knowledge has a positive impact on teaching and learning in STEM. Schulman (1986) suggests a distinction between the different content knowledge. The first one is the subject matter of content knowledge. Here, teachers have to go beyond facts and concepts. They need to explain in a way that gives meaning not only within the field but also across subjects. The second one is PCK, which is about knowing how to teach a subject through efficient representations/practices (Schulman, 1986). Such knowledge not only comes from teaching programs and research; it also comes through 
personal experiences. Also, it involves knowing what makes the learning of specific topics easy or difficult. The last one is curricular knowledge, which is related to the established curriculum (Schulman, 1986). Thus, research asserts that teachers who possess a well-developed STEM pedagogical content knowledge, a constructivist paradigm of teaching and learning, and an ability to draw on a vision while reflecting on and during teaching to help discuss challenges are well situated to engage in the practice of adaptive teaching (Mishra \& Koehler, 2006; Schulman, 1986).

In addition, teachers feel that by integrating a little sprinkle of technology and engineering mixed in mathematics and science is enough to integrate STEM across all four disciplines (Radloff \& Guzey, 2016; Stohlmann, 2018). This shows how one of the biggest educational challenges for K - 12 STEM education is that few general guidelines or models exist for teachers to follow regarding how to teach using STEM integration approaches in their classroom (Wang et al., 2011). Therefore, by drawing on the PCK notion proposed by Shulman (1986), Koehler and Mishra (2006) described the framework of TPACK (technology, pedagogy, and content knowledge), where technological knowledge, pedagogical knowledge and content knowledge interrelate with one another and co-work on the effectiveness of teaching and learning. Content knowledge has its most influence on curriculum design, which technology can either afford or constraint; pedagogical knowledge, including that of lesson plan, classroom management, as well as of student development and learning, transform "expert students" into "novice teachers", which is also influenced by technology nowadays (Koehler \& Mishra, 2006, p. 1023). Therefore, teaching professionals must be aware of this and take on this challenge by comprehensively and creatively integrating technology into their teaching for effective integrated STEM instruction. 


\section{Problem - Based Learning (PBL)}

Prior work (Breiner et al., 2012; Stohlmann, 2018; Wang et al., 2011) in STEM education suggests that when students have confidence in their capabilities in STEM classes as well as constructive attitudes toward STEM, they are more likely to be interested in and eventually pursue STEM-related courses and careers in post-secondary. Problem-based learning is an effective and valuable method that can guide students towards this constructive knowledge. Yackel \& Cobb (1996), present PBL as a teaching method in which real-world problems are used as the vehicle to promote student learning as opposed to passive instruction of facts and concepts. Yackel and Cobb (1996) worked within a grade two classroom which focused on a classroom where mathematical instruction followed a constructive tradition of PBL. They analyzed the construction of sophisticated conceptions of place-value numeration and increasingly efficient algorithms for adding and subtracting three-digit numbers. In this classrooms, teachers posed problems to the whole class, collaborative small groups work between pairs of children, and there was a follow up a whole class discussion where children explained and justified their solutions (Yackel \& Cobb, 1996). Further, through certain problems, teacher and students co-created the meaning of mathematical explanations, justifications and efficient solutions where the teacher and students established taken-as-shared meanings for tens and ones. The findings from this study showed how mathematical learning is a process of individual construction and it appears that PBL may be one such strategy for increasing students' interest in STEM fields. Encouraging students to self-direct (Anthony, 1996; Crawford \& Witte, 1990; Kelly \& Knowles, 2016; Simon, 1995) when challenged with a problem usually leads to a deep understanding, which in turn leads to better a recalling of resources and information. This is refining students to better appreciate the approaches often found within the STEM field, learning 
real-world perceptions within their classrooms. Thus, PBL reinforces and increases how students think about problems and offer tools that can help students creatively expand their thinking about solving problems of all types.

\section{Classroom Discourse.}

During curriculum integration, mathematical discourse allows teachers to monitor students' dispositions and measure their developing confidence and interest (Radloff \& Guzey, 2016; Wang et al., 2011). Further research (Draper, 2002; Simon 1995) expresses learning integrated STEM education beyond simply concepts, procedures, and their application. It also includes giving "students opportunities to express themselves through discourse as they work to construct and refine their thinking" (Draper, 2002; p. 388). For example, in Simon (1995)'s, case study which involved a group of preservice elementary teachers and a set of tasks designed to elicit understandings about how multiplication related to the algorithm of area $\mathrm{A}=\mathrm{L} \mathrm{x}$ W. Students used rectangles to measure the length and width of a table. Simon (1995) pushed students to explain how they found the area without defaulting to formula (p. 123). This led to class discussions where some students talked about rows and columns, some talked about counting rectangles, but comments about overlapping rectangles suggested misunderstanding was still apparent. Simon tried varying the task such as trying other activities to elicit better student explanations. As a result of Simon (1995), case study the classroom discussion in his study helped him push to reexamine students understanding on area and to further elaborate his own map of conceptual terrain as a teacher and students were able to go on to interpret and evaluate their solutions and effectively communicate their results with each other (Maab and Artigue, 2013; Simon, 1995). Rather than focusing on computational skills, the lesson was designed to develop higher - order thinking skills which were listed by Wang et al., (2011). In 
general, when offering STEM activities in informal settings, teachers recognize that the activities should not only be fun and engaging but also should also be related to instructional goals and supported in a practical and realistic understanding of what is involved in pursuing an interest in the topic involved.

Small Group. Small group exercises are one form of cooperative learning that can also be used in integrated STEM education (Anthony, 1996; Kyriacou, 1992). It is based on the principle of constructivism, with attention to the contribution that social interaction can make. Traditional instruction would use small group work as nothing more than learners working alongside each other, whereas curriculum integration requires group work to be much more than this (collaboration, sharing, ideas and discussion) (Kyricaou, 1992). As an example, Springer, Stanne, and Donovan (1999) established these results in their meta-analysis of 39 studies in university STEM classrooms. They discovered that students who took part in various types of small-group cooperative learning, ranging from extended formal interactions to concise informal interactions, had an increasingly academic achievement (Springer et al., 1999). This also exhibited more positive attitudes towards learning and had increased perseverance through STEM courses than students who did not participate in STEM small-group learning.

\section{Teachers' Role in a Constructivist Classroom}

The role of the teacher in such a constructivist classroom differs from traditional approaches and asks for pedagogies that foster students' construction of their knowledge through inquiry, exploring, and finding their own path to the solution (Simon, 1995). More specifically, the role of a constructivist teacher is to facilitate or assist students as they create construction (Anthony, 1996; Caswell \& LaBrie, 2017; Cobb \& Yackle, 1996; Draper, 2002; Kyriacou, 1992; Maab \& Artigue, 2013; Simon, 1995; Wang et al., 2011). In Simon (1995) case study which was 
explained earlier, we saw how the professor provided a structure and a set of plans that supported the development of informed exploration and reflective inquiry without taking imitative or control away from the students. The teachers' primary challenges concentrated on trying to keep the lesson real for students and struggling with better integrating math. Therefore, constructivism pedagogy requires that teachers take into consideration what "students know, what they want to know, and how to move students toward desired knowledge" (Draper, 2002, p. 528). The teacher's knowledge evolves simultaneously with the growth in the students' knowledge. As the students are learning in an integrated STEM classroom, the teacher is learning about the subject and about the thinking of his students (Simon, 1995).

Role as a planner. The teacher must design tasks and projects that stimulate the student to ask questions pose, problems, and set goals for an effective integrated STEM classroom (Huntley, 1998). Students will not become active learners by accident but by design through the use of the plans that teachers structure to guide exploration and inquiry (Kelly \& Knowles, 2016; Simon, 1995). It is, therefore, the responsibility of every teacher to plan activities that require a high level of cognitive demand. Simon (1995) first introduced hypothetical learning trajectories (HLT) as "a tool to plan instructional task based on predictions of how the students' thinking and understanding will evolve in the context of the learning activities" (p. 136). The HLT included three aspects: 1) the learning goal, 2) the instructional sequence of tasks to support those learning goals, and 3) the development progression of students expected as a result of the instructional sequence (Simon, 1995). The HLT is not intended to be a scripted lesson plan. Modification of the trajectory happens as the teacher increases their knowledge about what students understand, which can be during a planning session, between lessons or during a classroom activity. 


\section{Discussion \& Implication}

Research elaborated how integrated STEM education includes an exploration of the interconnections between science, technology, engineering and mathematics in order to reflect on how each discipline operates within real-world contexts. Students benefit from the integrated STEM approach because it values students' real-life experiences (Huntley, 1998; Kelley \& Knowles, 2016) and hands-on applications that mirror professional STEM work (Breiner et al, 2012; Wang et al., 2011; Ring et al., 2017). This approach prepares students as future citizens to approach societal complex problems. However, integrated STEM instruction remains ill-defined, with many gaps in the existing research. It has been found to be a difficult task for teachers (Briener et al., 2012, Huntely,1998; Kelley \& Knowles, 2016; Ring, 2017; Wang et al., 2011); for instance, teachers' limited access to resources and lack of teacher readiness to teach STEM can create challenges in implementing integrated STEM curricula (Wang et al., 2011).

On the other hand, research makes it visible that teacher's play an important role in curriculum integration. They need to observe development as students engage in discussions, supporting them as their knowledge grows and they become more skilled at expressing ideas reasonably and using terminology, composition, and semantics accurately in any of the STEM subjects (Briener et al., 2012). In addition, classroom discourse allows teachers to increase understandings not only about what students know, but also about the methods they use and how they understand the ideas and the ways they present their knowledge. However, it can be useful if further professional development on curriculum integration can be implemented for in service and pre-service teachers for integrated STEM classrooms to occur with increasing benefits. Indeed, research has created theoretical constructs and materials supporting curriculum integration approaches but, the effect on the day - to - day teaching remains limited. The 
question of what extent these objectives can really be reached and how far students content knowledge is effected by curriculum integration needs to be answered by research. 


\section{References}

Anthony, G. (1996). Active learning in a constructivist framework. Educational Studies in Mathematics, 31(4), 349-369. doi:10.1007/bf00369153

Breiner, J., Harkness, S., Johnson, C., \& Koehler, C. (2012). What is stem? a discussion about conceptions of stem in education and partnerships. School Science and Mathematics, 112(1), 3-11. doi: 10.1111/j.1949- 8594.2011.00109.x

Clements, D. H., \& Battista, M. T. (1990). Constructivist learning and teaching. Arithmetic Teacher, 38(1), 34-35. doi:10.1016/j.tate.2007.12.002

Crawford, M., \& Witte, M. (1999). Strategies for Mathematics: Teaching in Context. Educational Leadership, 57(3), 34-38. doi:10.1177/1555458916687600

Draper, R. J. (2002). School mathematics reform, constructivism, and literacy: A case for literacy instruction in the reform-oriented math classroom. Journal of Adolescent \& Adult Literacy, 45(6), 520-529. doi:10.1007/0-306-48380-7_3224

Huntley, M. A. (1998), Design and Implementation of a Framework for Defining Integrated Mathematics and Science Education. School Science and Mathematics, 98: 320-327. doi:10.1111/j.1949-8594.1998.tb17427.x

R. Kelley, Todd \& Knowles, John. (2016). A conceptual framework for integrated STEM education. International Journal of STEM Education, 3(10). doi:10.1186/s40594-016-0046z Kyriacou, C. (1992). Active learning in secondary school mathematics. British Educational Research Journal, 18(3), 309-318. doi:10.1080/0141192920180308

Maaß, K., \& Artigue, M. (2013). Implementation of inquiry-based learning in day-to-day teaching: a synthesis. ZDM: The International Journal of Mathematics Education, 45(6), 779-795. doi:10.1007/s11858-013-0528-0 
Mishra, P., \& Koehler, M. J. (2006). Technological Pedagogical Content Knowledge: $A$ Framework for Teacher Knowledge. Teachers College Record, 108(6), 1017-1054. doi:10.1111/j.1467-9620.2006.00684.x

Shulman, L. S. (2013). Those who Understand: Knowledge Growth in Teaching. Journal of Education, 193(3), 1-11. doi:10.1177/002205741319300302

Simon, M. A. (1995). Reconstructing mathematics pedagogy from a constructivist perspective. Journal for Research in Mathematics Education, 26(2), 114-145. doi:10.2307/749205

Stohlmann, M. (2018). A vision for future work to focus on the "M" in integrated STEM. School Science and Mathematics, 118(7), 310-319. doi:10.1111/ssm.12301

Springer, L., Stanne, M. E., \& Donovan, S. S. (1999). Effects of small-group learning on undergraduates in science, mathematics, engineering, and technology: A metaanalysis. Review of Educational Research, 96(1), 21-51. doi:10.2307/1170643

Radloff, J., \& Guzey, S. (2016). Investigating Preservice STEM Teacher Conceptions of STEM Education. Journal of Science Education and Technology, 25(5), 759-774. doi:10.1007/s10956-016-9633-5

Ring, E. A., Dare, E. A., Crotty, E. A., \& Roehrig, G. H. (2017). The Evolution of Teacher Conceptions of STEM Education Throughout an Intensive Professional Development Experience. Journal of Science Teacher Education, 28(5), 444-467. doi:10.1080/1046560x.2017.1356671

Wang, H., Moore, T., Roehrig, G., \& Park, M. (2011). Stem integration: Teacher perceptions and practice. Journal of Pre-College Engineering Education Research, 1(2). 1- 13. doi:10.5703/1288284314636 